\title{
LAS BIBLIOTECAS PRIVADAS \\ EN LOS PROTOCOLOS NOTARIALES. \\ VALENCIA 1780.1808
}

Genaro LAMARCA LANGA

"Estaban dominados por la biblioteca, por sus promesas y sus interdicciones. Vivian con ella, esperando, pecaminosamente, poder arrancarle algún dia todos sus secretos".

Umberto Eco. El nombre de la rosa. 

Las bibliotecas privadas como fuente para el estudio de la cultura y las mentalidades presentan numerosas dificultades ya expuestas desde hace años(1). Su estudio, sin embargo, no puede desdeñarse porque, analizadas de forma sistemática y en gran número, pueden ofrecer un panorama amplio y significativo de las corrientes ideológicas de las que se nutre el propietario, al menos, de esa biblioteca.

Ahora bien, las bibliotecas privadas que normalmente conocemos, o son las grandes, importantes por el número de ejemplares, o bien son aquéllas que por la significación de su propietario dan luz sobre su personalidad.

No obstante, no debemos limitarnos a este conocimiento fragmentario y seleccionado con criterios más o menos trascendentes, sino que más bien estas bibliotecas han de servirnos como tantas otras. O en todo caso, como contrapunto referencial para el estudio de las que posían las gentes vulgares, artesanos, mujeres o presbiteros beneficiados de cualquier pequeña parroquia; y éstas habrán de ser buscadas, sobre todo, en los protocolos notariales(2).

\section{LOS PROTOCOLOS NOTARIALES COMO FUENTE}

Si el estudio de las bibliotecas presenta numerosos y variados problemas, su estudio a través de los protocolos ofrece otras dificultades específicas(3).

La primera dificultad se presenta cuando observamos que algunas personalidades de las que no hay ninguna duda poseian bibliotecas, en algunos casos espléndidas, no la reflejan en su inventario en manera alguna(4). En otras ocasiones encontramos referencias tan pobres como en las que concretan tan sólo el número de "armarios de librería».

Esta falta de mención de las bibliotecas es quizá el problema de más difícil solución. Naturalmente en personajes conocidos, bien puede ser localizada en otras fuentes, o bien puede encontrarse alguna referencia indirecta que dé noticias sobre ella(5).

Pero, ¿qué ocurre con las personas anónimas, aquéllas que para la posteridad solamente dejan su nombre en sus parroquias y en algún que 
otro protocolo notarial?. Puede decirse de estas personas que, cuando hacen inventario post-mortem, una mayor pobreza suele corresponderse con un mayor detalle en la explicitacion de sus bienes, entre los cuales se cuentan los pocos libros que.pudiesen poseer. De hecho, hay indicaciones de libros en inventarios paupérrimos.

Por otro lado, para grupos más o menos intelectuales, como abogados o clérigos, en torno a un $90 \%$ de sus inventarios ofrece alguna confirmación de la existencia de libros o bibliotecas.

Probablemente los inventarios nobiliarios son los que presentan más problemas; apenas hay mención en un $53 \%$ de ellos y puede suponerse que, por el nivel social y económico de buena parte de los integrantes de este estamento, el número de bibliotecas fuera más abundante.

Dificultades de otro tipo presentan los inventarios en los que hay constancia de la existencia de libros pero no reflejan ninguno de sus títulos, ni su valor, ni la cantidad de ellos(6). Dentro de este grupo, un caso especial se da cuando se sabe que la lista se encuentra localizada en otro lugar. Hay noticias de dos bibliotecas de las que el Tribunal de la Santa Inquisición ha tomada buena nota(7).

Otra forma de conocimiento indirecto e incompleto aparece cuando encontramos la fórmula "únicamente se pondrá su total valor para evitar prolixidad,(8), u otra parecida; este dato, sin embargo, nos hace suponer la envergadura de la biblioteca.

En ambas situaciones, esta última y la anterior, aunque no podamos hacer un estudio detallado, sí, al menos, las referencias que dan permiten no falsear resultados totales, bien de cantidades, bien de relaciones por profesiones.

Una mayor información encontramos cuando los inventarios ya dan noticia del número total de libros, pero ¿manifiestan el número de títulos, 0 por el contrario, y más probablemente el número de volúmenes?. Esta duda entorpece mucho el estudio estadístico e impide que estos datos puedan ser utilizados con total seguridad para la búsqueda, por ejemplo, de tamaños medios de las bibliotecas( $(9)$.

La situación cambia profundamente cuando en los inventarios se ha recogido al menos el título o el autor de una obra. Estas mayores precisiones ya permiten un estudio cultural e ideológico, en algunos casos detallado. 
Naturalmente tampoco en este caso los problemas están ausentes; puede aparecer, por ejemplo, un sólo título o autor, citando además el número total o el valor de los libros de la biblioteca(10).

Sobre las bibliotecas en las que títulos o autores se detallan planea siempre una sospecha: ¿están recogidos todos los libros o por varias posibles razones, dos sobre todo, la relación es incompleta?. No estamos tratando en este caso de catálogos en los que de forma taxativa y explicita se relacionan unos cuantos libros y del resto solamente pone una cantidad, sino de aquéllos que aparentamente presentan la totalidad de la biblioteca. En los casos en los que podemos sospechar ocultamientos e incluso en los que aparece solamente la cantidad o el valor de los libros, surge la pregunta, el por qué. ¿Serán estos, los ocultados cuando los haya, los libros prohibidos?. Es posible, o ¿serán quizá los más usados y los más viejos?. Tampoco es descartable; es incluso lo más probable. De hecho cuando al final de un inventario aparece "un montón de libros viejos y usados valorados en..." u otra formulación parecida, la tasación suele ser muy baja en relación con las precedentes. Por otra parte, aunque no son muy abundantes, tampoco son desconocidos los títulos o autores prohibidos en los inventarios.

Otras dificultades son más puntuales y a pesar de que entorpecen sobre manera el estudio de estas bibliotecas, hasta hacerlo en algunas ocasiones casi imposible, son, sin embargo, de una índole muy diferente. Son, sobre todo, las pésimas referencias que presentan las bibliotecas de muchos inventarios, especialmente las pequeñas; en algunos casos aparece solamente el título muy incompleto o deficientémente escrito, en otras u autor sin especificar obra, etc.. Puede decirse que en muchos casos el escribano se limitaba a tomar lo escrito en el lomo de los volúmenes. Es todavia peor cuando puede suponerse que se los dictaban con el consiguiente resultado de amplios y muy variados errores.

Pese a las deficiencias de las anotaciones notariales, los ocultamientos, fuera una u otra su causa, la ausencia de cualquier explicitación de títulos o autores e incluso la falta de testimonio de existencia de libros en algunos inventarios de notables, el estudio de estas bibliotecas puede ser de gran valor para el conocimiento de la cultura e ideología del siglo XVIII, pues de sus análisis pueden ser extraídas numerosas conclusiones. Los variados problemas no invalidan los estudios, simplemente los dificultan. 
El trabajo se ha realizado con protocolos notariales de la ciudad de Valencia, entre los años 1740 y 1808, sobre 1.304 inventarios post mortem, incluyendo en ellos algunas divisiones de bienes que llevaban previo el inventario. La mayor parte de los libros de protocolos utilizados se encuentran en el Archivo de Protocolos del Colegio de Corpus Christi (A. P. P.) de los que se han visto la casi totalidad de escribanos de esas fechas; en menor medida se han utilizado libros del Archivo del Reino de Valencia (A. R. V.), en este archivo la selección de notarios ha sido absolutamente aleatoria, salvo en el caso del notario Joaquín Pastor, 1742-1797, del que se tenia noticia de su relación con el grupo mayansiano. En cada libro de cada notario se ha estudiado todos y cada uno de los inventarios que aparecían en todos los años revisados.

\section{LAS BIBLIOTECAS Y SUS PROPIETARIOS}

Los conceptos libro y biblioteca van a ser utilizados indistintamente; la simple presencia de un libro será considerada biblioteca, puesto que el objeto del trabajo es en primer lugar estudiar la presencia de libros en la sociedad valenciana del siglo XVIII.

La posesión, o no, por parte de una persona, de obras, impresas o manuscritas, en una sociedad que numéricamente es sobre todo analfabeta, puede ser uno de los aspectos más significativos a reseñar en un análisis como el presente. Entre los 1.304 inventarios estudiados ha aparecido noticia de la existencia de libros en 261 , es decir, en un porcentaje del $20 \%$, bastante bajo si lo comparamos con las ciudades del oeste francés en la misma época(11).

El análisis de conjunto del cuadro número 1, permite observar algunas características importantes como son, el alto número, 403, y porcentaje, 30,9 , de inventarios de artesanos, cifras que no se corresponden, como se podía presuponer, con la presencia de bibliotecas en ellos, tan sólo 8, lo que supone que solamente en el $2,4 \%$ de los inventarios de artesanos aparece alguna anotación sobre libros.

Entre los labradores la relación es aún más baja, de 192 inventarios hay tan sólo una mención a bibliotecas, es decir, no llega al $1 \%$ del total. 
Por el contrario de los 111 inventarios de clérigos, 100 citan al menos un libro, nada menos que el $90 \%$ (12).

Es muy bajo el número de inventarios femeninos, el 16,6\% considerablemente inferior al que Berger señala(13) para la Valencia del Renacimiento. Sorprende cuando consideramos que el número de testamentos es esencialmente idéntico entre ambos sexos en los pueblos valencianos de la época; sin duda esa cifra tan baja solamente puede ser relacionada con la muy débil posición económica de la mujer.

La evolución en la relación inventarios-bibliotecas que se da en todo este período, agrupados los inventarios por decenios de redacción, está recogida en el cuadro número 2.

Destaca previamente en el orden metodológico, que el número mayor de inventarios analizados se sitúa entre los añós 1760 y 1780 y que la cifra está, entre un mínimo de 127 , el $9,73 \%$, para el período $1800-1808$ y un máximo de 248 , el $19,01 \%$, para el decenio 1760-1769.

El análisis por columnas conduce a interesantes conclusiones. La columna $E$, que expresa la relación entre el número de inventarios y el de bibliotecas mantiene en todos sus periodos una gran homogeneidad; los años en los que ha aparecido una mayor presencia de libros, ha sido entre 1750 y 1759 , con un $23,85 \%$, la menor entre los años 1760-1769 con un $16,93 \%$. Como se ha señalado antes en total, el $20 \%$ de los inventarios muestra la presencia de libros. Es preciso también resaltar que la columna no marca ninguna tendencia, ni al alza ni a la baja.

Comparando la columna $\mathrm{C}$, es decir, el porcentaje de inventarios con la columna $\mathrm{F}$, el porcentaje de bibliotecas en cada uno de los decenios, se observa una correspondencia directa; las cifras más diferenciadas, lógicamente se dan también entre los años $1760-1769,19,01 \%$ y $16,09 \%$ y en el decenio $1750-1759$ invirtiendo máximo y mínimo $15,10 \%$ y $18 \%$.

La comparación entre ambas columnas tampoco permite establecer una relación de progresión o disminución en ningún sentido.

La conclusión es evidente, en este periodo en Valencia, no aumenta ni disminuye el número de bibliotecas en los inventarios. ¿Podemos deducir de ello que no aumenta el porcentaje de personas que tienen libros propios?. Con la salvedad que impone que los inventarios sean post morten, es decir, tiendan a reflejar en general, la situación de las edades maduras, parece que ésta es la conclusión más lógica que podemos extraer. 


\section{LAS BIBLIOTECAS DETALLADAS}

Hasta aquí se consideraba para el estudio la mera mención a libros, pero a continuación el análisis de las bibliotecas incluye solamente aquéllas que puede suponerse recogen en detalle todas las obras presentes en ellas, es decir, se excluyen las que sólo hablan de cantidad total o del precio de los libros, incluso aquéllas que aunque detallan parte de los libros, no lo hacen en su totalidad reseñando para el resto únicamente su cantidad, su valor material o la mera noticia.

El número de estas bibliotecas asciende a algo más de la mitad, 138; si nos atenemos a la verosimilitud de los inventarios, el 52,87\% de estas bibliotecas pueden considerarse completas en la enumeración de sus títulos o autores.

Entre todas ellas la media de títulos es de 105, sin embargo, la desviación standard es bastante elevada, 216; desviación explicable lógicamente porque se han estudiado conjuntamente bibliotecas con un solo título y con más de 1.000 .

El cuadro 3 recoge esta dispersión. Puede verse en él como el 26,08 \% de las bibliotecas tienen menos de 5 títulos, menos de 20 aparecen en el $42,02 \%$; el $60,14 \%$ tiene menos de 50 títulos. Por el contrario, el 23,18 superan los 100(14).

\section{ANALISIS SOCIAL}

No es un problema de fácil solución la clasificación por grupos homogéneos de indivíduos en el Antiguo Régimen. Una clasificación por estamentos presenta para el estado llano una enorme variedad y no es representativa de su gran dispersión social. Hay muchas otras posibles clasificaciones; en esta se ha partido de los dos grupos estamentales privilegiados, clero y nobleza; el estado llano se ha fragmentado en unidades profesionales definidas que se ha intentado sean concretas. Aparecen en algunos casos grupos profesionales tan poco significativos socialmente como los maestros de obras, por ejemplo, pero que permiten una mayor precisión en los análisis. 
Clero

Este grupo social que supone el $8,51 \%$ en los inventarios aparecidos, es sin embargo, de gran importancia pues la aparición de bibliotecas es de un $90,09 \%$. Es decir, un 38,31 de las bibliotecas aparecidas pertenecian a clérigos.

Además son los que permiten un estudio más detallado, pues como de las 100 bibliotecas, la alta cifra de 60 podemos considerar que precisan todos los libros, resulta que el $\mathbf{4 3 , 4 7} \%$ de las bibliotecas especificadas son de clérigos (ver cuadro 4).

La media es prácticamente la general, es decir, 103, pero la desviación standard es aún mayor, 273. Estos últimos datos son la consecuencia lógica de la aparición en este grupo de las más importantes, por su tamaño, bibliotecas; la de Asensio Sales, electo obispo de Barcelona, con más de 1600 títulos(15), la de Pascual Vicente Llansola con 1.196(16) o la de Francisco Pascual Chiva con $791(17)$. Merecen además reseñarse por su posible interés las bibliotecas de Vicente Casaña con 313 títulos(18) o la de Benito Casanova(19). La biblioteca de Juan Antonio Mayans no aparece porque los libros «encóntranse mezclados en la grande libreria de los difuntos señores don Gregorio Mayans y don Miguel Mayans» aunque más adelante se aclara que usegún una nota que ha encontrado entre otoros papeles [doña Teresa Josefa Vives, viuda de don Miguel Mayans] se compone de mil setecientos sesenta y ocho volúmenes de libros en octavo, quarto y foleo, encuadernados unos en pasta, otros en pergamino y otros en rústica», que estaban valorados en 22.500 reales(20).

Frente a estas bibliotecas, importantes en número e incluso en interés, la dispersión de muchas otras es enorme porque lógicamente son mucho más frecuentes aquéllas que sólo contienen un número muy reducido de volúmenes. Son varias las que contienen un solo título uun breviario valorado en...".

\section{Bibliotecas juridicas}

En cierto sentido las bibliotecas de los abogados ofrecen una situación más homogénea que las de los clérigos; la media por biblioteca es mayor, 186 títulos, y la desviación standard algo inferior a la media y muy 
por debajo de la de los clérigos, 169. La mayor biblioteca pertenecía a Joseph Boyl y reseñaba 570 títulos(21), la menor 5.

Como puede presumirse las 18 bibliotecas detalladas ofrecen una gradación en su tamaño bastante escalonada. Es preciso, además significar el alto porcentaje de bibliotecas detalladas, dos tercios exactamente.

Por la personalidad de su propietario, la biblioteca más destacable es la Thomás Fernández de Mesa, del año 1748, que detalla 400 títulos(22).

Los escribanos ofrecen un balance más modesto, una media de 79 títulos, con un máximo de tan sólo 201(23); sorprendentemente, quizá no muy confiados en sus colegas o absolutamente fiados en ellos, apenas la cuarta parte de los inventarios reflejan con precisión la biblioteca del difunto.

\section{Nobleza}

La nobleza, a pesar de las escasas referencias a libros en los inventarios, supone el grupo social que más detalla sus bibliotecas, prácticamente el $70 \%$.

La más destacada por el número de obras y de las que más por su contenido es la de don Antonio Ladrón de Pallás y Escrivá con 774 títulos(24). Otra digna de destacar, aunque no incluida estadísticamente en este apartado por no estar totalmente detallado, es la de don Joseph Caro Maza, Marqués de la Romana, del año 1749(25).

Es menester señalar que se han incluido 3 bibliotecas de mujeres nobles, porque su contenido responde al de cualquier otra biblioteca nobiliar(26), incluso una de ellas es de las reseñables por el titulo al que pertencian, los marqueses de Dos Aguas, que tenía 575 títulos en el año 1807.

La media de títulos en estas “librerías» es bastante superior a la general, 148 y la desviación standard es muy parecida a la absoluta, 223. Aparte de las grandes bibliotecas existian otras pequeñas, como la del caballero de la Orden de San Juan, don Joaquin Catalá y Calatayud, que detalla solamente 3 obras(27). 


\section{Comerciantes}

Las bibliotecas de los comerciantes presentan varios graves problemas. El primero es la propia definición de comerciante; no es infrecuente la aparición de un inventario con la indicación "...maestro terciopelero", u otros maestros, que sin embargo da toda una amplia relación de bienes que se encuentran en la tienda; otro grave problema se plantea al unificar en un solo apartado los pequeños tenderos y los grandes comerciantes; hay además noticias de amplias y especiales bibliotecas, como la de Bernardo Lasala, que no aparece en su amplio y detallado inventario(28); tenemos además la presencia de otros varios comerciantes franceses que la citan pero no la detallan "en una librería pequeña ochenta y dos libritos, los más en francés y seguramente muy inútilesw(29).

Entre las localizadas solamente dos son significativas por su amplitud, la de Roque Canet, que en el año 1792 tiene 93 obras $(30)$ y la de Pierre Lostau, del año 1748, con 407 títulos(31).

La escasez de bibliotecas detalladas resta validez a la media, que es de 84 títulos y a la desviación standard de 162.

\section{Médicos}

Las bibliotecas de los médicos valencianos de esta época, quizá pueden ser caracterizadas sobre todo por una gran homogeneidad en el tamaño, 28 títulos tiene la más pequeña plenamente detallada(32) y en torno a 455 la mayor, que era propiedad de una de las figuras de la medicina española del siglo XVIII, el catedrático de Medicina Mariano Seguer, cuyo inventario está fechado en el año 1754(33).

La cantidad de obras lleva a una media importante, 174 títulos, la misma prácticamente que la desviación standrad 172; para este grupo profesional la media es más significativa que en otros por la proximidad entre los extremos.

Parecería, a pesar de los datos, considerando que son solamente 5 las bibliotecas detalladas, aventurada la afirmación de que eran en general más amplias y homogéneas las bibliotecas médicas que las de otros grupos sociales (34). 


\section{Maestros de obra}

Arquitectos, maestros de obra y maestros albañiles forman un grupo reseñable. El sentido técnico de su profesión se ve reflejado tanto en la aparición de 7 bibliotecas en tan sólo 11 inventarios, el 53,84\%, como en la aparición de las herramientas que poseían.

La biblioteca que podría ser más interesante por su amplitud, la de Francisco Gascó, no refleja título de las obras, sino sólo cantidad, 26, valorados en 16 libras y 5 sueldos(35). Felipe Rubio, uno de los directores de las obras del edificio de la Aduana, hoy Palacio de Justicia, tenia una biblioteca en la que detalla 12 títulos(36).

La media es muy baja, tan sólo 7 títulos, muestra una gran homogeneidad en el volumen de libros que tenian todos ellos. De los inventarios que no detallan se puede, sin embargo, deducir que la cifra no seria muy diferente de ésta.

Funcionarios-y militares destacan por la igualdad del tamaño de sus bibliotecas y su baja media. La escasez de inventarios y bibliotecas consiguientemente, impiden llegar a conclusiones más terminantes.

\section{Libreros}

Los libreros suponen un capitulo aparte. Sus inventarios reflejan el catálogo de su negocio(37) y la precisión del número de títulos, en algunos casos va acompañada del número de ejemplares de cada obra y ésto supone no sólo un significativo sobrevalor respecto a los catálogos de libreria impresos, sino que puede tener un indudable valor para conocer la difusión de obras que por su escaso precio quizá se omitan en inventarios.

De las cuatro librerias localizadas solamente la de Manuel Fuster puede ser considerada relativamente importante y tenía detallados 821 títulos(38); los tres restantes más anónimos, suponen quizá un acercamiento más válido y generalizable, por ser tres pequeñas librerías(39).

\section{Bibliotecas femeninas}

Las mujeres se incluyen como grupo específico, aunque no sea ni estamental ni profesional; la posición de la mujer obligaba bien a incluirlas en los grupos profesionales de sus maridos, bien a formar con ellas un apartado especial. 
Suponen además una problemática especial, ¿sus bibliotecas son propias o las que recogen sus inventarios son con frecuencia de sus maridos o en su caso heredadas?.

No siempre es un asunto de fácil determinación; pero en la mayor parte de ellas el análisis de los contenidos lleva a la siguiente conclusión: las bibliotecas no les son propias en su totalidad; cabe la posibilidad de que en ellas estén incluidos algunos libros propios, pero la mayoría de los libros suelen ser profesionales, es decir del marido. Conviene señalar la paradoja que supone el que las que puede pensarse eran las mayores bibliotecas, no aparecen detalladas(40).

La mayor de las bibliotecas específicamente de mujeres, no está sin embargo, incluída en las estadísticas porque no detalla todos los títulos, incluye 13 obras, más 25 vidas de santos, sin especificar, y 34 libros utambién místicos» «14).

En su conjunto, las 7 bibliotecas que detallan su contenido ofrecen un muy pobre balance, una media de 3 títulos, con un máximo de 4;:y aunque se esté en la conciencia de que los resultados están probablemente algo alejados de la realidad, no dejan de señalar sin embargo una pobre situación que se acentuaría si se consideraran los contenidos de esas bibliotecas.

\section{Indeterminados}

En el apartado de indeterminados se incluye los 53 inventarios que no recogen la profesión del inventariado y cuyo testamento tampoco la especifica; su probable heterogeneidad profesional impide un análisis más detallado. Otro tanto ocurre con el apartado varios que recoge profesiones con la sola referencia a biblioteca.

Artesanos y labradores carecen prácticamente de bibliotecas, es éste el aspećto más reseñable. 


\section{NOTAS:}

(1) Véase M. Chevalier, Lectura y lectores en la Espafía de los siglos XVI y XVII. Ed. Turner, Madrid, 1976. Hay también muchas interesantes ideas a lo largo del Colloque de la Casa de Velázquez. Livre et lecture en Espagne et en France sous l'Acien Régime. Editions A.D.P.F., Paris, 1981. Es de esperar la próxima publicación de las actas del // Coloquio de Metodologia Historica Aplicada celebrado en Santiago de Compostela del 27 de septiembre al 1 de octubre de 1982; asi mismo se espera con interés la anunciada obra de F. López, Libro y sociedad en el siglo XVIII español.

(2) Con excelentes resultados han sido utilizados por J. Quéniart, Culture et société urbaines dans la France de l'Ouest au XVII/ siècle. Libraire C. Klincksiek, Paris, 1978.

Para el siglo XVIII gallego véase en A. Eiras Roel y colaboradores, La historia social de Galicia en sus fuentes de protocolos. Universidad de Santiago de Compostela, Santiago, 1981, B. Barreiro. "Las clases urbanas de Santiago en el siglo XVIII: definición de un estilo de vida y pensamienton, pp. 449-494 y O. Rey Castelao. «El clero urbano compostelano a fines del siglo XVIII: mentalidades y hábitos culturales", pp. 495- 519.

Para Barcelona en el siglo XVIII véase Moreu-Rey, E. "Sociologia del llibre a Barcelona al segle XVIII. La quantitat d'obres a les biblioteques particulars", Estudis Historics i documents dels arxius de protocols, n. ${ }^{\circ}$ VIII, 1980, Barcelona, pp. 275-303.

El renacimiento valenciano está siendo estudiado por Ph. Berger, véase especialmente "La lecture à Valence de 1474 à 1504 (quelques données numériques)». Mélanges de la Casa de Velázquez, T. X, pp. 99-118, De Boceard, Paris, 1975. También "La lecture à Valence de 1474 à 1560. (Evolution des comportaments en foction des milieux sociaux)n. Colloque de la Casa... pp. 97110.

(3) En el presente trabajo solamente va a hacerse referencia a las bibliotecas obtenidas de protocolos notariales. Por razones metodológicas las bibiiotecas conocidas por otras fuentes no van a ser consideradas.

(4) Un ejemplo muy significativo lo tenemos en la biblioteca de don Joaquin Antonio de Casteliví, Conde de Carlet, del año 1799, que éstá en vias de publicación por Salvador Albiñana y Genaro Lamarca. El catálogo de esta espléndida biblioteca se encuentra en el Archivo Municipal de Valencia, legado Serrano Morales, 4.445.

(5) De la biblioteca de Onofre Vicente Escrivá de Ixar del año 1688 hablan, al menos, V. Ximeno, Escritores del Reyno de Valencia, Valencia, 1747-1749, p. 145, col. 2 y J. Rodríguez, Biblioteca Valentina, Valencia, 1747, p. 358, col. 1.

(6) Como ejemplo puede servir utambién manifiesta [el Dr. José Marzal, albacea testamentario] ser de esta herencia todos los libros que se hallan en los estantes arriba inventariados que considerándolo por librería bastante voluminosa y ser preciso emplear mucho tiempo en su reconocimiento y tasación, reserva adiccionarle a este inventario y le ha parecido del caso inunciarlow. Del inventario de Nicolás Movera, Canónigo Doctoral de la Santa Iglesia Metropolitana. A. P. P., not. Vicente Francisco Furió, 407, 1774, f. 25 v. -32 v.

(7) La primera pertenecia a Ignacio Longás, Prebítero y Capellán mayor de Su Majestad en el Palacio Real de Valencia. "Hasta el presente no havía sido posible dar curso al citado inventario por haverse necesitado de la inspección de muchos dias para arreglar y concertar el indice del numeroso cuerpo de libros recayentes en dicha herencia y también el examen y aprobación dei Santo Oficio, en donde fue presentado y manifestadon. A. P. P., not. José Morales, 100, 1758, 
5-14 v. y 25 v.-29 v. La segunda pertenecía a Vicente Branchat, udel Consejo de Su Majestad y ohjdor de la Real Audiencia». "Primeramente una librería compuesta por varios cuerpos de libros en diferentes estantes por el abecedario, estimada por lo respectivo a su principal en setecientas setenta y dos libras y seis sueldos y en orden a varios libros de historia y otros asumptos en ciento setenta y siete libras y 13 sueldos de que se ha formado nota por menor y presentado al Santo Oficio de la Inquisición en 9 de agosto de este año, comprensiva de 18 fuxas rublicadas todas por el señor don Manuel Fuster y Beltrán, secretario de dicho Santo Oficio con el correspondiente permiso para hacer el uso que por los interesados se estime bajo la nota que en la misma se expresa». A. P. P., not. Joseph de Velasco, 146, 1971, f. 586.588.

(8) En el inventario de Thomás Ramos, cura párroco de San Martín. A. R. V., not. Vicente Seguí Rodríguez, 7.955, 1805, f. 318 v. -332 .

(9) Estos casos son bastante frecuentes en todo tipo de inventarios y refiriéndose a todo tipo de bibliotecas; desde un solo libro sin especificar autor ni título, hasta los 1915 a que se refiere el inventario de Ignacio Longás, veáse nota 7.

(10) Por ejemplo el inventario de Francisco Rodríguez Vallejo, Tesorero y Capellán del Arzobispo de Valencia recoge "104 libros valorados en 36 libras, después de extraer las obras de fray Luis de Granada para el Arzobispo y los libros legados a don Ignacio Monseny". A. P. P., not. Francisco Luis Simian, 1758, 55 v.-61 v.

(11) J. Quéniart. Ob. cit., p. 158.

(12) B. Barreiro da unos datos que pueden considerarse parecidos, ob. cit., p. 473.

(13) Ph. Berger. En Colleque de la Casa..., p. 99, afirma "le nombre des hommes est plus de deux foix supérier à celui des femmes».

(14) Un cuadro que recogiera la cantidad y la media de títulos por decenios no sería fiable. Conocida la fuerte dispersión en el número de títulos, la aleatoria colocación de las grandes bibliotecas en los distintos años y la escasez de estas, quedaba la solución de eliminar las grandes libręrias, pero ¿desde qué número?, ¿de 300 en adelante, que suponen solamente el 11.60 del total?. Ni considerando todas las bibliotecas, ni excluyendo las grandes los resultados son significativos; al contrario son muy variados y no merecen ninguna línea.

En el primer caso podemos encontrarnos con una media de 135 títulos para la década 1790 1799, y otra de 59 para la década 1760-1769; en el segundo caso y en la misma década 1790-1799 una media mínima de 21 y una máxima de 53 para los af́os $1770-1779$. Como puede verse, no parece necesaria la presencia de estos datos.

(15) A. P. P., not. Onofre Candado, 411, 1754, t. 20-70. También Moreu-Rey localizó el inventario con la biblioteca en el año 1755 a la que da un número de 1550 títulos, op. cit.

(16) A. P. P., not. Vicente Furio, 108, 1791, f. 50 v.-78.

(17) El bibliófiło mosen Chiva es un caso especial. Ya en 1759 había vendido, por mediación de Gregorio Mayans, al Pensionario de Rotterdam Meerman, una biblioteca completa, y para la fecha de su muerte, 1781, tenia esta obra de 791 títulos. A. R. V., not. Joaquín Pastor, 7.334, 1781, f. 676-696 v.

En la almoneda, f. 697 v., se recoge aDeseando dar entero y puntual cumplimiento a su en. cargo, haviendo tenido noticia positiva del IImo. Señor Don Francisco Pérez Bayer, Preceptor de los Serenisimos Infantes de España y Dignidad de Arcediano Mayor del Illo. Cabildo Eclesiástico de la Santa Metropolitana Iglesia de esta ciudad, en que expresava a su IIma. no le acomodava tomar por el todo la librería del citado mosen Chiva a causa de tener muchos libros y obras de las contenidad en ella y que podían los otorgantes ponerla en venta sin reparo alguno para cumplir con su encargon. 
(18) A. R. V., not. Joaquín Pastor, $7.316,1763,355$ v.-365 v.

(19) A. P. P., not. Joaquín Guardiola, 400, 1.758, 110 v.-118.

(20) A. P. P., not. Lorenzo Villel, 176, 1802, f. 274-274 v.

(21) A. P. P., not. Vicente Valor, 196, 1776, f. 135-147.

(22) A. P. P., not. Pedro Rodrigo, 145, 1748, f. 479-493.

(23) Especial reseña merece el inventario de Luis Vicente Simian, del año 1788, porque además de una biblioteca de 87 títulos, incluye un precioso catálogo de 65 grupos de partituras musicales que también permite ver la importancia de autores como Hayd o Boccherini, en la Valencia de la época. A. P. P., not. Nicolás Marco, 129, 1788, f. 414-419 v.

Otro catálogo musica, más rico que el anterior, con 113 referencias lo encontramos en el inventario de Ignacio Baeza y Mas de Pelayo, Regidor Perpetuo del Ayuntamiento de Valencia, en el año 1834. A. R. V., not. Antonio Jacques y Sánchez, 8.969, 1834, f. 935-965.

(24) A. P. P., not. Francisco José Nogués y Fabra, 92, 1780, f. 186-211 v. Esta biblioteca presenta algunos caracteres especiales, aparte del elevado número de títulos; trae al final una relación de libros prestados, que aún no han podido recuperarse en el momento de redactar el inventario, y de quien tiene cada libro en ese momento; entre estos se encuentra Pascual Vicente Llansola. Por otro lado en los excelentes indices elaborados en la Casa Profesa y el Colegio de San Pablo de la Compañía de Jesús de Valencia, tras su expulsión, aparece entre las bibliotecas de los aposentos de los padres o hermanos la presencia de 4 títulos probablemente procedentes de esta biblioteca. Las relaciones de libros de estas bibliotecas tienen un gran interés, tanto porque ofrecen las referencias bibliográficas con gran precision, como por señalar los libros comunes o de propiedad privada dentro de cada aposento; hay además una breve relación de libros prohibidos "que havía apartados en el aposento del P. Canicia». A. R. V., Sección Clero, legajos 59 y 63 .

(25) A. P. P., not. Joaquín Medina, 105, 1749, f. 222 v.-223.

(26) La primera de doña María Elena de Lanuza, Marquesa de Dos Aguas en A. P. P., not. Joseph Velasco, 146, 1807, f. 186 v.-211. La segunda de doña María Ceferina Carrillo, con 65 títulos, A. P. P., not. Mariano Chiarri, 2.189, 1805, f. 18-20. Y la tercera de la Marquesa Vda. de Castellfort, con 34 títulos, A. P. P., not. Vicente Francisco Furio, 407, 1770, f. 79-117.

(27) A. P. P., not. José Alvárez y Jordán, 459, 1784.

(28) A. P. P., not. Joseph Sanahuja, 151, 1744, f. 83 v.-114 y 140 v.-144.

(29) A. P. P., not. Thomás Vinet, 295,1781 , f. 67 v. -85 v.

(30) A. P. P., not. Thomás Rodríguez, 180, 1792, f. 56-117.

(31) A. P. P., not. Joseph Sanahuja, 151, 1748, f. 87-131 v.

(32) En la biblioteca de Luis Paches, A. P. P., not. Vicente Valor, 196, 1766, f. 191 v.-195 v.

(33) A. P. P., not. Pasqual Meseguer, 106, 1759, f. 16 v. 31.

(34) La biblioteca de Cristóbal Micó constaba de «diferentes obras en foleo, quarto y octavo de poca entidad" valoradas en 1 libra y 10 sueldos. A. P. P., not. Luis Vicente Simian, 202, 1756, f. $1-4$ v.

Hay también una excelente biblioteca de Vicente Pons, Cirujano Mayor del Hospital Real y General que detalla 54 títulos y se afirma que hay más. A. R. V., not. Carlos Vicente Segui Rodriguez, $7.958,1803$, f. 270 v.-275 v. 
Las bibliotecas que con el epigrafe médicos, aparecen en el cuadro 3 , incluyen las de dos cirujanos, uno de ellos el citado Vicente Pons, y la de un boticario. En el cuadro 4, son todas de médicos.

(35) A. R. V., not. Joaquín Pastor, 7.335, 1982, f. 512 v.-520.

(36) A. P. P., not. Joseph Peregrín Mascarós, 104, 1767, f.

(37) Las especiales características de estos catálogos obligan a marginar estas librerías en el tratamiento estadístico de los datos. Ninguna de ellas ha sido tenida en cuenta para la elaboración de los análisis, salvo para las cifras totales de bibliotecas localizadas.

(38) Esta biblioteca establece una diferencia entre libros en su vivienda "Libros existentes en la sala enquadernados en pasta y pergamino" y "Libros del mercadon. A. P. P., not. Lorenzo Villel, 176,1793, f. 25-66.

(39) Estos tres libreros son Joaquín Minguet, que detalla unos 361 títulos, A. P. P., not. Nicolás Marco, 129, 1793, f. 180-192. Pedro Miró detalla 174, A. P. P., not. Francisco Hidalgo Ca. valler, 418, 1772, f. 13-25. Y Manuel López con 170, A. P. P., not. Joseph Escoin, 349, 1805, f. 369 v.377.

(40) Así, por ejemplo, en el inventario de Juana Mustieles, cuyo marido era el maestro arquitecto Manuel Fornés, aparece la referencia a una biblioteca valorada en 46 libras y 10 sueldos, sin más indicación que ésta. A. R. V., not. Carlos Soliva, 8.002, 1807, f. 15 v.-17.

(41) Se trata de Vicente Mora. A. P. P., not. Miguel de la Orden, 102, 1784, f. 93 v.-100 v. 


\begin{tabular}{|c|c|c|c|c|}
\hline & $A$ & $B$ & $\mathrm{C}$ & D \\
\hline Clérigos .... & 111 & $8 \times 51$ & 100 & $90 ׳ 09$ \\
\hline Abogados.... & 31 & $2 \times 37$ & 27 & $87 \times 09$ \\
\hline Escribanos... & 29 & $2 \cdot 22$ & 8 & $27 \cdot 58$ \\
\hline Nobles & 43 & $3 \cdot 29$ & 23 & $53 \cdot 48$ \\
\hline Comerciantes & 118 & 904 & 17 & $14: 40$ \\
\hline Médicos .... & 28 & $2 ‘ 14$ & 11 & $39 \cdot 28$ \\
\hline Artesanos & 403 & $30 \times 90$ & 8 & $2^{\prime} 41$ \\
\hline Funcionarios ... & 20 & $1 ‘ 53$ & 7 & 35 \\
\hline Arquitectos ... & 13 & $0 ‘ 99$ & 7 & $53 ‘ 84$ \\
\hline Militares ................ & 22 & $1 ‘ 68$ & 4 & $18 ‘ 18$ \\
\hline Libreros ............ & 4 & $0: 30$ & 4 & 100 \\
\hline Labradores & 192 & $14 \cdot 72$ & 1 & $0 ‘ 58$ \\
\hline 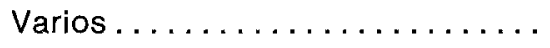 & 20 & $1: 53$ & 3 & 15 \\
\hline Mujeres & 217 & $16^{\prime} 64$ & 27 & $20 \cdot 14$ \\
\hline Indeterminados ......... & 53 & $4^{‘} 06$ & 14 & $26^{\circ} 41$ \\
\hline TOTAL $\ldots \ldots \ldots \ldots \ldots$ & 1.304 & 100 & 261 & 20 \\
\hline
\end{tabular}

Columna A: Número de inventarios encontrados en cada profesión. Columna B: Porcentaje de inventarios de cada profesión.

Columna C: Número de inventarios en que aparecen bibliotecas.

Columna D: Porcentaje de inventarios que recogen alguna referencia a libros. 


\section{CUADRO 2}

\begin{tabular}{|c|c|c|c|c|c|}
\hline A & B & $\mathrm{C}$ & $D$ & $E$ & $F$ \\
\hline $1740-49 \ldots \ldots$ & 132 & $10^{\prime} 12$ & 30 & $22 \cdot 72$ & $11^{\prime} 49$ \\
\hline $1750-59 \ldots \ldots$ & 197 & $15^{\prime} 10$ & 47 & $23^{\prime} 85$ & $18^{\prime} 00$ \\
\hline $1760-69 \ldots \ldots$ & 248 & $19^{\circ} 01$ & 42 & $16 ’ 93$ & $16 ، 09$ \\
\hline $1770-79 \ldots \ldots$ & 243 & $18^{\prime} 63$ & 44 & $18^{\prime} 10$ & $16^{\prime} 85$ \\
\hline $1780-89 \ldots \ldots$ & 201 & $15^{\prime} 41$ & 44 & $21 ‘ 89$ & $16 \cdot 85$ \\
\hline $1790-99 \ldots \ldots$ & 156 & $11 ‘ 96$ & 29 & $18 ‘ 58$ & $11 \cdot 11$ \\
\hline $1800-08 \ldots \ldots \ldots$ & 127 & 973 & 25 & $19^{\prime} 68$ & $9 \cdot 57$ \\
\hline $1740-08 \ldots \ldots \ldots$ & 1.304 & 100 & 261 & & 100 \\
\hline
\end{tabular}

Columna A: Decenios.

Columna B: Número de inventarios por decenio.

Columna C: Porcentaje de inventarios por decenio.

Columna D: Número de bibliotecas.

Columna E: Porcentaje de inventarios con biblioteca en ese decenio. Columna F: Porcentaje de bibliotecas correspondientes a ese decenio. 


\section{CUADRO 3}

\begin{tabular}{|c|c|c|}
\hline A & $B$ & C \\
\hline $1-4 \ldots$ & 36 & $26^{\circ} 08$ \\
\hline $5-19$ & 22 & $42^{\prime \prime} 02$ \\
\hline $20-49$ & 25 & $60 ` 14$ \\
\hline $50-99 \ldots$ & 23 & $76 \times 81$ \\
\hline $100-299$ & 16 & $88^{\prime} 40$ \\
\hline $300-749$ & 12 & $97 \cdot 10$ \\
\hline $750-1499$ & 3 & $99 \cdot 27$ \\
\hline+ de 1500 & 1 & 100 \\
\hline
\end{tabular}

Columna A: Tamaño de las bibliotecas.

Columna B: Número de bibliotecas.

Columna C: Porcentaje de bibliotecas sumados los porcentajes anteriores. 


\section{CUADRO 4}

\begin{tabular}{|c|c|c|c|c|c|c|c|}
\hline & A & B & c & $D$ & $\dot{E}$ & $F$ & $G$ \\
\hline Clérigos & 100 & 60 & 60 & 1.600 & -1 & 103 & 275 \\
\hline Abogados... & 27 & 18 & $66 ‘ 66$ & 570 & 5 & 186 & 169 \\
\hline Escribanos....... & 8 & 6 & 75 & 201 & 3 & 79 & 73 \\
\hline Nobles....... & 23 & 16 & $69: 56$ & 774 & 3 & 148 & 223 \\
\hline Comerciantes ..... & 17 & 6 & $35 \cdot 29$ & 407 & 1 & 84 & 162 \\
\hline Médicos...$\ldots \ldots$ & 11 & 5 & $45^{\circ} 45$ & 455 & 28 & 174 & 172 \\
\hline Artesanos......... & 8 & 1 & $12{ }^{\prime} 5$ & - & - & - & \\
\hline Funcionarios . .... & 7 & 2 & $28 ` 57$ & 46 & 6 & 26 & 28 \\
\hline Arquitectos ...... & 7 & 3 & $42 \cdot 85$ & 12 & 1 & 7 & 6 \\
\hline Militares ..... & 4 & 2 & 50 & 31 & 5 & 18 & 18 \\
\hline Libreros .......... & 4 & 4 & - & - & - & - & - \\
\hline Labradores........ & 1 & 0 & - & - & - & - & - \\
\hline Varios ........... & 3 & 1 & $33: 33$ & - & - & - & - \\
\hline Mujeres.......... & 27 & 7 & $25 \div 92$ & 4 & 2 & 3 & 1 \\
\hline Indeterminados & 14 & 7 & 50 & 111 & 2 & 43 & 38 \\
\hline TOTAL. & 261 & 138 & $52 ' 87$ & 1.600 & 1 & 105 & 216 \\
\hline
\end{tabular}

Columna A: Número de inventarios con referencias a libros.

Columna B: Número de bibliotecas detalladas.

Columna C: Porcentaje de bibliotecas detalladas.

Columna D: Número de libros de la biblioteca mayor.

Columna E: Número de libros de la biblioteca menor.

Columna F: Cifra media de títulos en cada grupo profesional.

Columna G: Desviación standard. 